\title{
La Ley de Seguridad Nacional de Hong Kong
}

Hong Kong National Security Law

\begin{abstract}
El Comité Permanente de la Asamblea Nacional Popular de la República Popular China ha aprobado en junio de 2020 e introducido en el ordenamiento jurídico de la Región Administrativa Especial de Hong Kong la conocida como Ley de Seguridad Nacional de Hong Kong. El presente trabajo tiene como objeto analizar procedimental y materialmente la ley, relacionándola con el contexto sociopolítico de Hong Kong, dado que su aprobación no ha estado exenta de críticas. Por un lado, el sector afín al gobierno central chino defiende la legitimidad de la norma y afirma que la nueva ley ayudará a Hong Kong a salir de los crecientes disturbios que lleva sufriendo desde 2019. Por otro lado, el sector prodemocrático defiende la ilegitimidad de la norma, supuestamente por invadir competencias legislativas regionales y haciendo quebrar, en consecuencia, el principio político: «Un país, dos sistemas».
\end{abstract}

PALABRAS CLAVE: Ley de Seguridad Nacional, Hong Kong, República Popular China, Comité Permanente, Asamblea Popular Nacional, Región Administrativa Especial.

In June 2020, the Standing Committee of the National People's Congress of the People's Republic of China passed the so-called National Security Act of Hong Kong, and therefore inserted it into Hong Kong Special Administrative Region's legal order. The objective of this paper is to analyze the content and procedure of said Act, and to place it within Hong Kong's current sociopolitical context, given that its adoption has given rise to many a critique. On the one hand, those akin to China's central government defend the new Act's legitimacy and argue that it will help Hong Kong tackle the growing public disturbances it suffers since 2019. Conversely, the pro-democracy sector defends the new Act's illegitimacy, arguing that it overlaps with regional legislative competences, therefore breaking the fundamental principle of «one country, two systems».

KEYWORDS: National Security Law, Hong Kong, People's Republic of China, Standing Committee, National People's Congress, Special Administrative Region.

\section{Contexto sociopolítico hasta mayo de 2020}

Para situarse correctamente en la actualidad sociopolítica de Hong Kong podría usarse como referencia un artículo publicado en el número 3 de esta misma revista con ocasión del fallido 
proyecto normativo de extradición en Hong Kong ${ }^{1}$, donde se expone la compleja organización territorial de la República Popular China, el status jurídico-constitucional que se le concede de Hong Kong basado en el principio «Un país, dos sistemas» y el proyecto normativo de extradición que motivó una oleada de protestas durante el año 2019. No conviene reiterar aquí todo lo expuesto en el artículo mencionado, pero sí hacerle referencia y afirmar resumidamente que:

1) Hong Kong es una Región Administrativa Especial de la República Popular China con un sistema político, económico y jurídico que difiere notablemente del existente en el resto de la China continental. Sus particularidades jurídicas nacen de la comúnmente llamada Ley Básica de Hong Kong², oficialmente denominada Ley Fundamental de la Región Administrativa Especial de Hong Kong de la República Popular China.

2) Este status especial duraría 50 años a contar desde 1997, en virtud de la Declaración conjunta sino-británica de $1984^{3}$, por lo que Hong Kong posee transitoriamente un régimen especial hasta 2047, momento en el que su situación jurídico-administrativa pasaría a depender exclusivamente del gobierno central de la República Popular China.

3) Al margen de otro tipo de protestas que han existido hasta entonces, en marzo de 2019 se inició, por parte del ejecutivo hongkonés dirigido por Carrie Lam, un proyecto normativo de extradición que permitiría, en casos muy concretos y tasados, el traslado a la China continental de delincuentes.

4) La elaboración del proyecto desató durante varios meses una oleada de protestas y críticas al considerarse, por parte de un considerable sector de población hongkonesa y por diversos medios de comunicación, que dicho proyecto podría suponer una merma de autonomía política y jurídica en la región en favor del gobierno central chino.

5) Dicho proyecto finalmente fue retirado el 4 de septiembre de 2019 y las protestas, aunque continuaban tras su retirada, fueron poco a poco reduciéndose.

A los continuos meses de protestas, la consecuente merma del turismo y la incipiente recesión económica de la región, se sumó el inicio de una escalada en la crisis sanitaria internacional producida por la COVID-19, cuyo máximo impacto en Hong Kong se produjo en febrero y marzo de 2020, lo que redujo la posibilidad de movilizar multitudes y promovió que el ejecutivo impusiera como medidas de prevención restricciones tanto al modo como al número de personas que podían permanecer simultáneamente en actos públicos. Esto significó, entre otras cosas, que se iniciase un relativo período de «calma» por lo que respecta al prolongado tiempo de protestas y disturbios masivos que se llevaban produciendo desde 2019.

Pero la calma llegó a su fin el 8 de mayo de 2020, cuando se produjo una trifulca entre los parlamentarios prodemócratas ${ }^{4}$ y los afines al gobierno central chino en la reunión del Comité de la Cámara del Consejo Legislativo de Hong Kong, cuyo motivo estribaba en quién debía asumir

1. Borraz García, G. (2020). El proyecto normativo de extradición de Hong Kong. Revista Internacional Jurídica y Empresarial (3), 123-129. https://doi.org/10.32466/eufv-r.i.j.e.2020.3.579.123-129 (fecha de consulta 18/10/2020).

2. https://www.basiclaw.gov.hk/en/basiclawtext/images/basiclaw_full_text_en.pdf (fecha de consulta 18/10/2020). Este es el texto completo de la Ley Básica de Hong Kong. En lo sucesivo, en este trabajo, cuando se haga referencia a un precepto de la Ley Básica, este será traducido y expuesto con una finalidad facilitadora, pero es recomendable acudir a esta nota para poder consultarla en el propio documento oficial.

3. https://www.cmab.gov.hk/en/issues/jd2.htm (fecha de consulta 18/10/2020).

4. Entendiendo como prodemócratas a los defensores de una permanencia en la autonomía política y jurídica regional. 
la dirección de este órgano, encargado de examinar los proyectos de ley. Dicha trifulca supuso la expulsión de varios parlamentarios, reanudándose entonces los disturbios en las calles en apoyo a los parlamentarios prodemócratas, que habían estado paralizados los meses anteriores.

En suma, el conflicto social y político sigue presente en la región de Hong Kong. Frente al conflicto social, derivado del conflicto político y puramente concreto, que consiste en la organización de protestas violentas y disturbios, solo caben las medidas reactivas, como el envío de personal militar o policial antidisturbios que reprima y disuelva dichas protestas violentas. Pero, frente al conflicto político, que es estrictamente abstracto, existe la posibilidad de tomar medidas legales preventivas que pretendan reducir el número y la intensidad de los disturbios actuales y promover la eliminación del conflicto social, así como la instauración de una paz social con vocación de permanencia. Este tipo de medidas y la justificación del órgano que las toma son las que interesa analizar en este trabajo, y no el debate político sobre la idoneidad o no de las mismas. En este sentido, la medida más famosa que se ha tomado recientemente es la conocida como «Ley de Seguridad Nacional de Hong Kong», oficialmente llamada «Ley de la República Popular China de Salvaguardia de la Seguridad Nacional en la Región Administrativa Especial de Hong Kong», aprobada por el poder legislativo central de la República Popular China y promulgada por el ejecutivo hongkonés de Carrie Lam5.

\section{Motivación política de la ley}

La Asamblea Popular Nacional ${ }^{6}$-conocida a veces como Congreso Nacional Popular- celebra uno de los eventos políticos más trascendentes del país. En la tercera sesión de la XIII Legislatura de la Asamblea Popular Nacional, celebrada entre los días 22 y 28 de mayo de 2020 , los poderes de la República Popular China han buscado una solución al conflicto de la Región Administrativa Especial de Hong Kong. Para ello, el día 22 de mayo de 2020 se presentó ante dicha Asamblea un borrador de la Ley de Seguridad Nacional de Hong Kong.

Al presentar el borrador, el vicepresidente del Comité Permanente de la Asamblea Popular Nacional, Wang Chen, explicó la motivación oficial de dicho proyecto, que consta reflejada también en el mismo documento y que equivaldría a una «exposición de motivos»:

Desde el regreso de Hong Kong a la patria, China ha venido implementando firmemente los principios de «un país con dos sistemas», «el pueblo de Hong Kong gobierna Hong Kong» y una autonomía de alto grado. La práctica de «un país con dos sistemas» ha logrado un éxito sin precedentes en Hong Kong. Sin embargo, los riesgos de seguridad nacional cada vez más notables en Hong Kong se han convertido en un problema importante, citando las actividades que desafiaron seriamente el concepto del principio de «un país con dos sistemas», perjudicaron el Estado de derecho y amenazaron la soberanía, la seguridad nacional y los intereses de desarrollo de la nación. El documento indica que se deben tomar medidas legales y con-

5. LN 136 of 2020 B2345 https://www.gld.gov.hk/egazette/pdf/20202444e/es220202444136.pdf (fecha de consulta 18/10/2020).

6. Supremo órgano legislativo de la República Popular China. 
tundentes para prevenir, detener y sancionar tales actividades. El Artículo 23 de la Ley Básica de Hong Kong ${ }^{7}$ estipula que Hong Kong debe promulgar sus propias leyes para prohibir cualquier acto de traición, secesión, sedición, subversión contra el Gobierno Popular Central o robos de secretos de Estado, prohibir a las organizaciones u organismos políticos extranjeros realizar actividades políticas en Hong Kong y prohibir a las organizaciones u organismos políticos de Hong Kong establecer vínculos con organizaciones u organismos políticos extranjeros. Sin embargo, más de 20 años después del regreso de Hong Kong, las leyes relevantes aún no se han materializado debido al sabotaje y la obstrucción de quienes intentan sembrar problemas en Hong Kong e incluso en el resto de China, así como de las fuerzas hostiles externas. Teniendo en cuenta la situación actual en Hong Kong, se deben hacer esfuerzos a nivel estatal por establecer y mejorar el sistema legal y sus mecanismos de aplicación en Hong Kong para salvaguardar la seguridad nacional, para cambiar el Estado «indefenso» a largo plazo en campo de la seguridad nacional. Esto hará avanzar la construcción institucional para salvaguardar la seguridad nacional en el marco de la Constitución de China y la Ley Básica de Hong Kong. Esto también fortalecerá el trabajo de salvaguardar la seguridad nacional y garantizará el crecimiento estable y duradero de la causa de «un país con dos sistemas».

\section{Constitucionalidad conforme al sistema jurídico chino}

Partiendo de la anterior exposición de motivos políticos, conviene analizar los artículos 18 y 23 de la Ley Básica de Hong Kong, así como los preceptos a los que estos se remiten.

El artículo 18 de la Ley Básica de Hong Kong ${ }^{8}$ enumera las leyes que poseen vigor en la Región Administrativa Especial de Hong Kong. Estas son la propia Ley Básica de

\footnotetext{
7. Artículo 23 de la Ley Básica de Hong Kong: «La Región Administrativa Especial de Hong Kong promulgará leyes por sí sola para prohibir cualquier acto de traición, secesión, sedición, subversión contra el Gobierno Popular Central o robo de secretos de Estado, para prohibir que organizaciones u organismos políticos extranjeros realicen actividades políticas en la región, y prohibir a las organizaciones u órganos políticos de la región establecer vínculos con organizaciones u órganos políticos extranjeros». Este artículo sintetiza la autonomía legislativa de Hong Kong en las materias penales señaladas. 8. Artículo 18 de la Ley Básica de Hong Kong: «Las leyes vigentes en la Región Administrativa Especial de Hong Kong serán esta Ley, las leyes previamente vigentes en Hong Kong según lo dispuesto en el Artículo 8 de esta Ley y las leyes promulgadas por la legislatura de la región. Las leyes nacionales no se aplicarán en la Región Administrativa Especial de Hong Kong, excepto las enumeradas en el Anexo III de esta Ley. Las leyes allí enumeradas se aplicarán localmente mediante promulgación o legislación de la región. El Comité Permanente de la Asamblea Popular Nacional puede agregar o eliminar de la lista de leyes en el Anexo III después de consultar a su Comité de la Ley Básica de la Región Administrativa Especial de Hong Kong y al gobierno de la región. Las leyes que se enumeran en el Anexo III de esta Ley se limitarán a las relativas a la Defensa y Relaciones Exteriores, así como a otras materias fuera de los límites de la autonomía de la región según lo especifica esta Ley. En el caso de que el Comité Permanente de la Asamblea Nacional Popular decida declarar un estado de guerra o, debido a una agitación dentro de la Región Administrativa Especial de Hong Kong que ponga en peligro la unidad o seguridad nacional y esté fuera del control del gobierno de la región, decida que la región se encuentra en estado de emergencia, el Gobierno Popular Central puede emitir una orden aplicando las leyes nacionales pertinentes en la región».
} 
Hong Kong, las leyes vigentes anteriormente en el territorio en los términos del artículo 8 de la Ley Básica ${ }^{9}$ y las leyes que dicte la propia administración hongkonesa. Pese a que, en un principio, el precepto excluye las leyes nacionales -es decir, las dictadas por el poder legislativo de la República Popular China-, exceptúa las enumeradas en el Anexo III de la propia Ley Básica de Hong Kong ${ }^{10}$, que son leyes nacionales aprobadas por el poder legislativo de la República Popular China y que «se aplicarán» a la región. Estas leyes nacionales podrán ser añadidas o eliminadas del Anexo III por la Asamblea Popular Nacional, previa consulta de su Comité de la Ley Básica de Hong Kong y al gobierno regional hongkonés.

Y esta vía del artículo 18 es la que ha seguido el poder legislativo de la República Popular China para introducir su Ley de Seguridad Nacional de Hong Kong el 30 de junio de 2020. Hasta lo que se ha expuesto, no parece haber ningún elemento que impida o dificulte la introducción de la ley por esta vía, pero el artículo 18 no finaliza ahí.

Continúa el citado precepto estableciendo una limitación por razón de la materia a las normas que pueden incluirse en el Anexo III, que son las referidas a Defensa, Relaciones Exteriores o materias fuera de los límites de la autonomía legislativa hongkonesa, aunque estos límites podrán ser obviados en caso de ser declarado el estado de guerra o el estado de emergencia y, dado que desde 1997 no se ha declarado el estado de guerra o el de emergencia, no procede hablar de esta última vía para introducir la Ley de Seguridad Nacional de Hong Kong.

Tampoco la Ley de Seguridad Nacional está referida a cuestiones de Defensa o Relaciones Exteriores, dado que no existe ninguna justificación oficial que apele a dichas materias para incluirla por esa vía. Queda entonces por ver si la materia está encuadrada en la autonomía legislativa hongkonesa o no. Si no lo estuviera, la Asamblea Popular Nacional tendría plena justificación para poder incluir la Ley de Seguridad Nacional en el Anexo III de la Ley Básica de Hong Kong, pero el artículo $23^{11}$ de esta especifica lo contrario, puesto que tal y como se reconoce en el propio borrador de la Ley de Seguridad Nacional refiriéndose al propio artículo 23 de la Ley Básica, «Hong Kong debe promulgar sus propias leyes para prohibir cualquier acto de traición, secesión, sedición, subversión contra el Gobierno Popular Central o robos de secretos de Estado, prohibir a las organizaciones u organismos políticos extranjeros realizar actividades políticas en Hong Kong y prohibir a las organizaciones u organismos políticos de Hong Kong establecer vínculos con organizaciones u organismos políticos extranjeros».

Entonces, queda claro que, en principio y por razón de la materia, la Ley de Seguridad Nacional quedaría fuera de la normativa que la Asamblea Nacional Popular puede incluir en el Anexo III de la Ley Básica de Hong Kong para que esté vigente en la Región Administrativa Especial de Hong Kong.

9. Artículo 8 de la Ley Básica de Hong Kong: «Las leyes previamente vigentes en Hong Kong, es decir, el Common Law, las reglas de equidad, las ordenanzas, la legislación subordinada y el derecho consuetudinario se mantendrán, excepto aquellas que contravengan esta Ley, y sujeto a cualquier enmienda por parte de la legislatura de la Región Administrativa Especial de Hong Kong».

10. Que son un conjunto de leyes nacionales con aplicabilidad local en Hong Kong, por ejemplo, la Ley de Nacionalidad de la República Popular China.

11. Véase la nota 7. 
Ahora bien, pese a reconocerse expresamente este extremo en el propio borrador, la Asamblea Nacional Suprema, justificándose en la omisión de regulación del legislativo regional durante más de 20 años, se considera legítima para recuperar tal competencia y realizar tal tarea, máxime sabiendo que la única tentativa del legislativo hongkonés de dictar una ley de seguridad y así cumplir con la competencia del artículo 23 de la Ley Básica que culminó en un estrepitoso fracaso debido a las enormes protestas que se desataron en 2003 por su planteamiento, lo que obligó a archivarla. En suma, lo que la Asamblea Popular Nacional parece afirmar es que la competencia legislativa hongkonesa para una determinada materia solo es válida si esta se ha llevado efectivamente a cabo en un contexto sociopolítico que reclama tal regulación y en un contexto temporal razonable. Si una autoridad política cede tal competencia a otra, pero dicha competencia no se ejecuta cuando precisa ser razonablemente ejecutada, es lógico que la autoridad política cedente recupere tal competencia.

Independientemente de que se compartan políticamente o no los motivos esgrimidos por la Asamblea Nacional Popular para justificar su competencia e introducirla en el Anexo III de la Ley Básica de Hong Kong para desplegar su fuerza jurídica en el territorio regional, la pregunta que interesa es saber es si estos motivos son suficientes como para que la Ley de Seguridad Nacional de Hong Kong sea jurídicamente constitucional.

A este respecto Guoqiang Zhai ${ }^{12}$ recuerda que existen tres principales modelos de control constitucional en el mundo: el modelo de tribunal constitucional, presente en la mayoría de los países europeos como España o Alemania y que consiste en la existencia de un órgano jurisdiccional especial independiente encargado de dirimir las controversias constitucionales; el modelo de revisión judicial, presente por ejemplo en Estados Unidos o Japón en la que los jueces comunes revisan la constitucionalidad de las leyes y actos estatales, y el modelo de control parlamentario, presente por ejemplo en China, en el que el poder legislativo es el que dicta, interpreta y decide sobre la constitucionalidad de las leyes. En este último caso, y tal como señala el artículo 67 de la Constitución de la República Popular China $^{13}$, será el Comité Permanente de la Asamblea Popular Nacional el encargado de interpretar la Constitución y las leyes.

Por todo lo anterior se puede concluir que, jurídicamente, la Ley de Seguridad Nacional de Hong Kong es constitucional conforme al sistema jurídico de la República Popular China y que, por tanto, la interpretación para su inclusión en el Anexo III de la Ley Básica de Hong Kong es igualmente constitucional; necesita tan solo cumplir con los requisitos formales restantes del artículo 18 de la Ley Básica de Hong Kong ${ }^{14}$, que sería la previa consulta al Comité de la Ley Básica de la Región de Hong Kong y al gobierno de la región, el cual tras dicha consulta aplicará localmente la ley mediante su promulgación o legislación de la región.

12. Guoqiang, Z., «La práctica del control de constitucionalidad en China», Derecho PUCP: Revista de la Facultad de Derecho, ISSN 0251-3420, ISSN-e 2305-2546, n. 71, 2013, págs. 589-602. https://dialnet.unirioja.es/descarga/articulo/4906556.pdf (fecha de consulta 18/10/2020).

13. Artículo 67 de la Constitución de la República Popular China: «El Comité Permanente de la Asamblea Popular Nacional ejerce las siguientes funciones: 1) Interpretar la Constitución y supervisar su cumplimiento. 2) Elaborar y reformar todas las leyes, excepto las que deban ser elaboradas por la Asamblea Popular Nacional. 3) Complementar y modificar en forma parcial, en el tiempo comprendido entre los periodos de sesiones de la Asamblea Popular Nacional, las leyes elaborada por ésta, pero sin contradecir los principios fundamentales de estas leyes. 4) Interpretar las leyes».

14. Véase nota 8. 


\section{Estructura formal}

Oficialmente llamada «Ley de la República Popular China de Salvaguardia de la Seguridad Nacional en la Región Administrativa Especial de Hong Kong» ${ }^{15}$ y conocida como «Ley de Seguridad Nacional de Hong Kong ${ }^{16}$, fue aprobada por la Asamblea Nacional Popular a través de su Comité Permanente el 30 de junio de 2020, entrando en vigor el mismo día, integrándose en el Anexo III de la Ley Básica de Hong Kong mediante su promulgación por el gobierno regional de Carrie Lam.

La ley posee 66 artículos y está dividida en seis capítulos, de los cuales el capítulo Il está dividido en dos partes y el capítulo III está dividido en seis partes ${ }^{17}$.

\subsection{Capítulo I. Principios generales (artículos 1 a 6)}

El capítulo I posee seis artículos, en los cuales se expone que la ley trata de salvaguardar la seguridad nacional previniendo y castigando los delitos de secesión, subversión, terrorismo y colusión con países u organizaciones extranjeras que supongan un peligro para la seguridad nacional, garantizándose al mismo tiempo el principio de «Un país, dos sistemas», la estabilidad en la región y los derechos institucionales, colectivos e individuales de los hongkoneses siempre que no vulneren la seguridad nacional en los términos de la propia ley.

\subsection{Capítulo II. Los deberes y órganos de gobierno de la Región Administrativa Especial de Hong Kong para salvaguardar la seguridad nacional (artículos 7 a 19)}

\subsubsection{Parte I. Deberes (artículos 7 a 11)}

Se establece un mandato hacia los poderes públicos de Hong Kong para que completen lo antes posible, con regulación regional, las disposiciones legales relativas a la seguridad nacional en los términos de la Ley de Seguridad Nacional, tratando al mismo tiempo de reforzarla promoviendo su sensibilización a través de los medios de comunicación, internet, organizaciones sociales y educación, informando a los hongkoneses sobre la obligatoriedad de esta. De su actuación rendirá cuentas anualmente el ejecutivo de la región ante el gobierno central.

De este mandato parece desprenderse que la Asamblea Nacional Popular ha establecido unos mínimos indisponibles y de cumplimiento inmediato para Hong Kong, dejando abierta la vía legislativa regional para completar, mas no contravenir $^{18}$, lo dispuesto en la Ley de Seguridad Nacional.

15. Para el análisis de la Ley se ha tomado como referencia la traducción al inglés ofrecida por la Agencia de Noticias oficial del gobierno chino Xinhua: http://www.xinhuanet.com/english/2020-07/01/c_139178753.htm (fecha de consulta 18/10/2020); también está disponible su traducción en https://www.chinadaily.com.cn/a/202007/01/WS5efbd6f5a310834817256495.html (fecha de consulta 18/10/2020).

16. En adelante LNS.

17. En el presente trabajo se tratará de seguir, para su exposición, la estructura formal original, aunque algunas disposiciones serán mencionadas en otra parte de la norma en las que no están incluidas formalmente pero sí materialmente, o bien serán citadas como nota explicativa con una finalidad meramente didáctica y para dar transversalidad a la norma. 18. Corresponde al Comité Permanente de la Asamblea Popular Nacional la interpretación de la LSN y, por tanto, decidir si la normativa regional de desarrollo contraviene o no a esta. Vid. infra. 


\subsubsection{Parte II. Órganos de gobierno (artículos 12 a 19)}

Son tres los órganos que el gobierno regional deberá crear, cuyos gastos estarán sufragados por un fondo especial del que dispondrá el secretario financiero, previa aprobación del jefe del Ejecutivo de Hong Kong. Estos órganos son el Departamento para la Salvaguardia de la Seguridad Nacional, el Comité para Salvaguardia de la Seguridad Nacional y la División Especializada de la Fiscalía para la persecución de delitos contra la seguridad nacional y otros conexos.

1) Departamento para la Salvaguardia de la Seguridad Nacional: estará integrado en la Fuerza Policial de Hong Kong. El jefe del mencionado departamento será nombrado por el jefe del Ejecutivo de Hong Kong. Para la asistencia en sus labores podrá contratarse personal profesional y técnico fuera de la región. Las funciones del departamento son obtener y analizar información para poder planificar, coordinar y aplicar medidas que favorezcan la seguridad nacional e investigar delitos que afecten a la misma. También realizarán las funciones que le sean encomendadas por el Comité de Salvaguardia de la Seguridad Nacional.

2) Comité para la Salvaguardia de la Seguridad Nacional: será supervisado por el gobierno central chino. Estará presidido por el jefe del Ejecutivo de Hong Kong y el resto de miembros serán el secretario principal de Administración, el secretario financiero, el secretario de Seguridad, el secretario de Justicia, el comisionado de la Policía, el director de Inmigración, el comisionado de Aduanas, el director de la Oficina del Ejecutivo y el jefe del Departamento para la Salvaguardia de la Seguridad Nacional de la fuerza policial hongkonesa.

Dentro del Comité se creará también una secretaría dirigida por un secretario general nombrado por el gobierno central previa designación del jefe del Ejecutivo hongkonés.

El Comité contará con un asesor de Seguridad Nacional nombrado por el gobierno central chino, que prestará asesoramiento en materia de seguridad nacional y sobre las funciones del comité. El asesor asistirá a las reuniones del Comité.

Las funciones del Comité serán analizar, formular políticas, mejorar el sistema jurídico y de observancia, promover el desarrollo y coordinar las cuestiones relativas a la seguridad nacional. Ninguna entidad existente en la región ya sea institucional, colectiva o individual, podrá interferir en su trabajo. La información relativa a las labores del Comité no serán objeto de publicidad y sus decisiones no estarán sometidas a control judicial.

3) División especializada de la fiscalía para la persecución de delitos contra la seguridad nacional y otros conexos. El jefe de la división será nombrado por el jefe del Ejecutivo de Hong Kong. Los fiscales serán nombrados por el secretario de Justicia previo consentimiento del Comité de Salvaguardia de la Seguridad Nacional.

\subsection{Capítulo III. Delitos y penas (artículos 20 a 39)}

\subsubsection{Parte I. Secesión (artículos 20 y 21)}

Será condenado como reo de secesión la persona que organizare, planeare o cometiere los siguientes hechos o participare en los mismos empleando la fuerza o amenazando con usarla, 
con el fin de conseguir la secesión territorial o socavar la unidad nacional: separar, entregar a un país extranjero o alterar por medios ilícitos la situación jurídica de la Región Administrativa Especial de Hong Kong o cualquier otro territorio de la República Popular China.

El autor principal del delito, así como el que lo haya cometido de un modo grave, será condenado a la pena de prisión permanente ${ }^{19} \mathrm{o}$ a una pena de prisión ${ }^{20}$ por tiempo no inferior a 10 años. La persona que haya participado activamente será condenada a una pena de prisión por tiempo no inferior a tres años y no superior a diez años. Los demás participantes serán condenados a una pena de prisión inferior a tres años, detención de corta duración ${ }^{21}$ o restricción ${ }^{22}$.

El que incitare, asistiere o financiare con dinero o bienes a otras personas para que estas cometan el delito de secesión, tendrá una pena que se graduará en función de la gravedad del delito. Si el delito fuere grave, será condenado a una pena de prisión no inferior a cinco años ni superior a diez años. Si el delito fuere menos grave, será condenado a una pena de prisión inferior a cinco años, detención de corta duración o restricción.

\subsubsection{Parte II. Subversión (artículos 22 y 23)}

Será condenado como reo de subversión la persona que organizare, planeare o cometiere los siguientes hechos o participare en los mismos empleando la fuerza o amenazando con usarla u otros medios ilícitos con el fin de subvertir la facultad del Estado: derrocar o socavar el sistema constitucional de la República Popular China; derrocar los organismos de poder central de la República Popular China o los organismos de poder de la Región Administrativa Especial de Hong Kong; interferir gravemente, interrumpir o socavar el desempeño de los deberes y funciones legales de los organismos de poder central de la República Popular China o los organismos de poder de la Región Administrativa de Hong Kong, y atacando o dañando las instalaciones y locales utilizados por los organismos de poder de la Región Administrativa de Hong Kong para desempeñar sus deberes y funciones, inhabilitándolos para tal fin.

El autor principal del delito, así como el que lo haya cometido de un modo grave, será condenado con la pena de prisión permanente o a una pena de prisión por tiempo no inferior a diez años. La persona que haya participado activamente será condenada a una pena de prisión por tiempo no inferior a tres años y no superior a diez años. Los demás participantes serán condenados a una pena de prisión inferior a tres años, detención de corta duración o restricción.

El que incitare, asistiere o financiare con dinero o bienes a otras personas para que estas cometan el delito de secesión, tendrá una pena que se graduará en función de la gravedad

19. La LSN define la pena de prisión permanente como «life imprisonment», que debe entenderse equivalente al concepto jurídico regional «imprisonment for life».

20. La LSN define la pena de prisión como «fixed-term imprisonment», que debe entenderse equivalente al concepto jurídico regional «imprisonment».

21. La LSN define la pena de detención de corta duración como «short-term detention», que debe entenderse equivalente al concepto jurídico regional «imprisonment» para nacionales mayores de 21 años, "detention in a training centre» para nacionales mayores de 14 años y menores de 21 años (en virtud de la Cap. 280 Training Centres Ordinance de la RAEHK, https://www.elegislation.gov.hk/hk/cap280!en, fecha de consulta 18/10/2020) y «detention in a detention centre» para extranjeros.

22. La LSN define la restricción como «restriction», que debe entenderse equivalente a los conceptos jurídicos regionales «detention in a reformatory school» para menores de 14 años (en virtud de la Cap. 225 Reformatory Schools Ordinance, https://www.elegislation.gov.hk/hk/cap225, fecha de consulta 18/10/2020) o "community service». 
del delito. Si el delito fuere grave, será condenado a una pena de prisión no inferior a cinco años ni superior a diez años. Si el delito fuere menos grave, será condenado a una pena de prisión inferior a cinco años, detención de corta duración o restricción.

\subsubsection{Actividades terroristas (artículos 24 a 28)}

Será condenado como reo de terrorismo la persona que organizare, planeare o cometiere las siguientes actividades terroristas o participare o amenazare con participar en las mismas, causando o intentando causar grave daño a la sociedad con el fin de coaccionar al gobierno central popular, al gobierno de la Región Administrativa Especial de Hong Kong o a una organización internacional, o intimidando al público para conseguir una determinada agenda política: violencia grave contra una o varias personas; explosión, incendio o diseminación de sustancias venenosas o radiactivas, patógenos o enfermedades infecciosas u otras sustancias; sabotaje de medios de transporte o instalaciones de transporte, energía eléctrica, gas, combustible o explosivos; grave interrupción o sabotaje de sistemas de control electrónico para la prestación y gestión de servicios públicos como agua, energía eléctrica, gas, transporte, telecomunicaciones e internet, y otras actividades graves que pongan en peligro la salud pública, la seguridad o la protección.

La persona que cometa el delito causando lesiones corporales graves, muerte o pérdida significativa de propiedades públicas o privadas será condenada a una pena de prisión permanente o a una pena de prisión mayor de diez años. En otras circunstancias, la persona que cometa el delito será condenada a la pena de prisión mayor de tres años, pero menor de diez años.

La persona que organizare o se hiciere cargo de una organización terrorista ${ }^{23}$ será condenada a pena de prisión permanente o a pena de prisión mayor de diez años y podrán ser decomisados sus bienes ${ }^{24}$. La persona que participare activamente en una organización terrorista será condenada a una pena de prisión mayor de tres años e inferior a diez junto a una pena de multa. Otros participantes serán condenados a prisión inferior a tres años, detención de corta duración o restricción, todas ellas junto una pena de multa ${ }^{25}$.

La persona que prestare apoyo, asistencia o facilidades tales como entrenamiento, armas, información, fondos, suministros, trabajo, transporte, tecnología o lugares a un terrorista, a una organización terrorista o para la comisión de actividades terroristas, así como para este último fin, manufacturar o poseer ilegalmente sustancias patógenas de enfermedades infecciosas, radiactivas, explosivas, venenosas u otras, será condenada a la pena de prisión no inferior a cinco años ni superior a diez años, así como a una pena de multa o decomiso de sus bienes si el delito fuere grave. En otro caso, será condenado a una pena de prisión de hasta cinco años, detención de corta duración o restricción, todas ellas junto a una pena de multa. En caso de que el delito anterior entrara en concurso ideal con otros delitos, será castigado y sentenciado por el delito que tenga la pena más severa.

23. Entendiendo como tales aquellas organizaciones que cometieren o tuvieren intención de cometer actividades terroristas, así como las que participaren o asistieren.

24. La LSN define el decomiso de bienes como "confiscation of property», que debe entenderse equivalente al concepto jurídico regional "confiscation of procedes of crime».

25. La LSN define la pena de multa como «criminal fine», que debe entenderse equivalente al concepto jurídico regional «fine». 
La persona que hiciese apología del terrorismo o incitare a la comisión de actividades terroristas será condenado a una pena de prisión no inferior a cinco años ni superior a diez años, a una pena de multa o al decomiso de sus bienes si el delito fuere grave. En otro caso, será condenado a una pena de prisión de hasta cinco años, detención de corta duración o restricción, todas ellas junto a una pena de multa.

\subsubsection{Parte IV. Colusión con países u organizaciones extranjeras que supongan un peligro para la seguridad nacional (artículos 29 y 30)}

La persona que robare, espiare, obtuviere mediante pago o ilegalmente proporcionare secretos de Estado o inteligencia concerniente a la seguridad nacional para un país, institución, organización o individuo extranjeros ${ }^{26}$, o que con estos conspirare o a ellos solicitare o recibiere directa o indirectamente instrucciones, control, financiación u otro tipo de apoyo para cometer alguno de los siguientes actos ${ }^{27}$ será condenado a la pena de prisión permanente o prisión no inferior a diez años si el delito fuere grave, o a la pena de prisión de no menos de tres años ni superior a diez en otro caso: librando una guerra contra la República Popular China; usando la fuerza o amenazando con usarla para socavar su soberanía, unidad e integridad territorial; perturbar gravemente la formulación y aplicación de leyes o políticas por el gobierno regional o el gobierno central; manipular o socavar una elección en la región; provocando por medios ilícitos el odio entre los residentes de Hong Kong y el gobierno regional o central28, e imponer sanciones o bloqueos, o participar en otras actividades hostiles contra la región o el resto de la República Popular China.

\subsubsection{Parte V. Otras disposiciones penales (artículos 31 a 35)}

Las entidades, tales como empresas u organizaciones, legalizadas o sin legalizar, que cometan un delito prescrito en esta ley serán condenadas a la pena de multa. En tal caso, sus operaciones serán suspendidas y sus licencias o permisos comerciales revocados ${ }^{29}$. Si por la comisión de delitos, la entidad hubiere obtenido productos, incluyendo como tales las ganancias, ayudas, recompensas, herramientas y fondos usados o con intención de ser usados en la comisión delictiva, estos serán incautados y confiscados.

La pena impuesta podrá ser más leve, reducida o incluso eximida ${ }^{30}$ cuando voluntariamente el delincuente, acusado o sospechoso, desista de la comisión del delito o evite sus consecuencias durante el proceso de comisión delictiva, se entregue y confiese la verdad del delito ${ }^{31}$ o denuncie verazmente que el delito lo cometió otra persona o provea de información material útil en la resolución de otro caso criminal.

26. Las penas serán igualmente aplicables a la institución, organización o individuo extranjero involucrado.

27. Cuando la conspiración o la recepción directa o indirecta de instrucciones, control, financiación u otro tipo de apoyo, se hace para cometer secesión o subversión, ha de remitirse, respectivamente, a la parte I y parte II anteriormente descritas para que se impongan las penas más severas allí contenidas.

28. En estas tres últimas actuaciones enumeradas hay que añadir la precisión jurídica final de «que probablemente provoquen serias consecuencias».

29. La LSN define revocación de licencias o permisos comerciales como «revoke licence or business permit», que debe entenderse equivalente al concepto jurídico regional «revoke registration or exemption from registration, or revoke licence». 30. En caso de que el delito sea menos grave.

31. Esto también será aplicable al sospechoso o acusado que confiese verazmente que ha cometido otros delitos contenidos en esta ley de los cuales las autoridades no tienen constancia. 
Si la persona culpable de uno de los delitos contenidos en esta ley no es un residente permanente de Hong Kong podrá ser deportada como pena única o adicional a las mencionadas para el caso concreto. Podrá ser deportado también en caso de que contravenga las previsiones legales, pero no pueda ser enjuiciado por cualquier razón.

La persona juzgada y condenada por un delito contra la seguridad nacional quedará inhabilitado para ser candidato a un cargo público ${ }^{32}$. Si la persona juzgada y condenada es un cargo público ${ }^{33}$ será removido del cargo e inhabilitado para ser candidato u ocupar a partir de entonces cualquier otro cargo público. La remoción y la inhabilitación será anunciada por las autoridades competentes para organizar y dirigir las elecciones, el nombramiento o la remoción de cargos públicos.

\subsubsection{Parte VI. Ámbito de aplicación (artículos 36 a 39)}

La LSN se aplicará a la persona que cometa los delitos contenidos en la misma en el territorio de la Región Administrativa Especial de Hong Kong. Se entenderá también cometido en dicho territorio cuando un acto constitutivo de delito o sus consecuencias se produzcan en él, así como cuando los delitos se produzcan a bordo de naves o aeronaves registradas en la región.

Aunque el delito se cometa fuera de la región, la ley será igualmente aplicable en el caso de que el autor del delito contenido en esta ley sea un residente permanente en la Región Administrativa Especial de Hong Kong o una entidad, ya sea empresa u organización, legalizada o sin legalizar, que esté establecida en la región.

Aunque el delito lo cometa una persona que no sea residente permanente en la región, le será aplicada la ley si cometiere los delitos prescritos en la misma contra la región.

\subsection{Capítulo IV. Jurisdicción, ley aplicable y procedimiento (artículos 40 a 47)}

\subsubsection{Jurisdicción}

La región ${ }^{34}$ será competente para conocer todos los casos concernientes a los delitos prescritos en la LSN, excepto los que le competan a la Oficina para la Salvaguardia de la Seguridad Nacional ${ }^{35}$. Los tribunales conocedores de las materias relativas a la seguridad nacional son: los tribunales de magistrados, los tribunales de distrito, el Alto Tribunal y el Tribunal de Apelación Final. El jefe del Ejecutivo regional podrá designar a varios jueces de entre toda la región y de entre todos los niveles para integrar dichos tribunales, siempre que ninguno de los designados haya hecho declaraciones o tenido comportamientos que pongan en peligro la seguridad nacional. Su mandato será de un año y podrán ser destituidos si durante su mandato manifiestan alguno de los comportamientos prescritos anteriormente.

\footnotetext{
32. Expresamente se mencionan los cargos públicos en los órganos regionales como el Consejo Legislativo, los Consejos distritales y Comité electoral, pero la inhabilitación se extiende a cualquier cargo público regional.

33. Ya sea nacional o regional, así como electo o no, político o funcionario.

34. Sus órganos regionales preexistentes y los creados ex profeso por la Ley de Seguridad Nacional.

35. Véase apartado 4.5.
} 


\subsubsection{Ley aplicable}

Tanto la LSN como las leyes de la Región de Hong Kong serán aplicables a todas las cuestiones procesales, desde la fase de investigación hasta la fase de ejecución, respecto a los delitos por los que se tenga jurisdicción regional en virtud de la LSN.

\subsubsection{Procedimiento}

No se incoará ningún procedimiento sin el consentimiento por escrito del secretario de Justicia, pero esto no impedirá que se pueda proceder al arresto y detención del sospechoso o la prestación de fianza ${ }^{36}$.

Durante la investigación, el Departamento para la Salvaguardia de la Seguridad Nacional será el encargado de adoptar medidas tendentes al cumplimiento de la ley y al esclarecimiento de los hechos ${ }^{37}$, que serán supervisadas responsablemente por el Comité para la Salvaguardia de la Seguridad Nacional, que junto con el jefe del Ejecutivo regional podrán establecer reglas generales de actuación.

Se establece el principio acusatorio y el juicio se llevará a cabo en sesión pública del tribunal, aunque, cuando se vean involucrados en el juicio secretos de Estado o cuestiones de orden público, la sesión se celebrará a puerta cerrada, impidiéndose a los medios de comunicación y al público general el conocimiento de todo o parte del juicio, aunque la resolución sí que será dictada en sesión pública. Asimismo, las autoridades nacionales y regionales, policiales y judiciales, así como abogados, instituciones, organizaciones e individuos que se ocupen o participen en casos relacionados con delitos que afecten a la seguridad nacional, mantendrán el deber de confidencialidad en cuanto a los secretos de Estado y cualquier otra información relacionada.

\subsection{Capítulo V. Oficina para la Salvaguardia de la Seguridad Nacional del Gobierno Popular Central en la Región Administrativa Especial de Hong Kong (artículos 48 a 61)}

El Gobierno Popular Central financiará y establecerá en la Región Administrativa Especial de Hong Kong una Oficina para la Salvaguardia de la Seguridad Nacional ${ }^{38}$, integrada por personal designado por el gobierno central chino, supervisado por las autoridades nacionales y sujeto a las leyes nacionales y regionales. Los órganos regionales prestarán apoyo y facilidades a la Oficina en el cumplimiento de sus deberes, deteniendo y responsabilizando a quien obstruya el cumplimiento de estos.

La Oficina desempeñará su mandato en estricto cumplimiento de la legalidad y será supervisada en los términos legalmente previstos. Establecerá un mecanismo de coordinación

36. Aunque no se concederá fianza en caso de que el juez tenga motivos suficientes para creer que el sospechoso podrá seguir cometiendo actos que pongan en peligro la seguridad nacional.

37. Se enumeran múltiples medidas tales como búsqueda de locales, vehículos, retención del pasaporte, decomiso de bienes, interceptación de comunicaciones, vigilancia encubierta, interrogatorios, etc.

38. En adelante, la Oficina. 
con las autoridades regionales y, especialmente, con el Comité para la Salvaguardia de la Seguridad Nacional para supervisar y proporcionar orientación en el desempeño de su labor.

Sus funciones serán: efectuar análisis, evaluaciones del desarrollo, opiniones ${ }^{39}$ y propuestas estratégicas y políticas relativas a la salvaguardia de la seguridad nacional; supervisar, guiar, coordinar y prestar soporte a la región en materias relativas a la salvaguardia de la seguridad nacional; recopilar y analizar inteligencia e información concerniente a la seguridad nacional, y ejercer funciones en casos concernientes a delitos que pongan en peligro la seguridad nacional en los términos legalmente previstos ${ }^{40}$.

Centrándose en la última función mencionada, será el gobierno central chino, a petición de la propia Oficina o a propuesta del gobierno regional, el que apruebe la competencia para ejercer jurisdicción. En tal caso, la Oficina abrirá la investigación, la Fiscalía Popular Suprema ${ }^{41}$ designará un fiscal y el Tribunal Popular Supremo ${ }^{42}$ designará un órgano judicial para resolver.

En este caso excepcional en el que la Oficina tenga jurisdicción, serán aplicables, a todas las fases del proceso, la Ley de Enjuiciamiento Criminal de la República Popular China y las demás leyes nacionales, desde la fase de investigación hasta la fase de ejecución, teniendo fuerza jurídica en la región. El personal al servicio de la Oficina y sus actuaciones en el ejercicio de esta competencia, así como los titulares de una identificación o de un certificado expedido por la Oficina, sus vehículos, artículos y documentos, están fuera de la jurisdicción y del control de las autoridades regionales. Asimismo, el personal de la Oficina disfrutará de los demás derechos e inmunidades reconocidos en la legislación regional.

El sospechoso tendrá derecho a la asistencia jurídica letrada, a un juicio justo y sin dilaciones indebidas, y todo aquel que tenga información relativa al delito contra la seguridad nacional enjuiciado está obligado a testificar verazmente.

\subsection{Capítulo VI. Disposiciones complementarias (artículos 62 a 66)}

Cuando las disposiciones de la Ley de Seguridad Nacional entren en conflicto con las disposiciones de las leyes regionales, prevalecerán aquellas sobre estas ${ }^{43}$.

La interpretación de esta ley es competencia del Comité Permanente de la Asamblea Popular Nacional ${ }^{44}$.

39. Entre sus funciones, hay que especificar que la Oficina será la encargada de efectuar un dictamen por escrito que le será solicitado por parte del jefe del Ejecutivo antes de proceder al nombramiento del jefe del Departamento para la Salvaguardia de la Seguridad Nacional y el de la División Especializada de la Fiscalía para la persecución de delitos contra la seguridad nacional y otros conexos. Aunque no se especifique, a juicio del autor debe entenderse que el dictamen es preceptivo y vinculante.

40. Pese a que, con carácter general, la jurisdicción la ejercen los órganos regionales en los términos de la Ley de Seguridad Nacional, la Oficina y los órganos nacionales serán competentes, de forma excepcional, cuando se haya producido una inminente y gran amenaza a la seguridad nacional, cuando el caso sea complejo debido a la participación de un país extranjero o de elementos externos o cuando una situación grave suceda e impida al gobierno regional hacer cumplir eficazmente esta ley.

41. Es el órgano de fiscalía superior de la República Popular China.

42. También llamado «Corte Suprema Popular», es el órgano judicial superior de la República Popular China.

43. Lo que supone que la LSN tenga una posición de primacía sobre el resto del ordenamiento jurídico regional.

44. Debe entenderse, por tanto, que cualquier laguna legal, consideración, cuestión o concreción que deba ser objeto de interpretación, quedará resuelta a criterio de este órgano. 
La ley entrará en vigor en la fecha de su promulgación ${ }^{45}$.

La ley se aplicará a los actos que se produzcan tras su entrada en vigor ${ }^{46}$.

\section{Conclusiones}

La Ley de Seguridad Nacional de Hong Kong, redactada por el Comité Permanente de la Asamblea Popular Nacional de la República Popular China, regula materias que, en principio, y en virtud de la Ley Básica de Hong Kong, le corresponde regular a los órganos legislativos regionales. No obstante, el Comité Permanente ha utilizado argumentos políticos y jurídicos que hacen, en virtud de su competencia constitucional para interpretar las leyes y decidir sobre la constitucionalidad de estas, que su legalidad y constitucionalidad no pueda ser cuestionada conforme al ordenamiento jurídico de la República Popular China. Por tanto, y utilizando la vía excepcional que le concede la propia Ley Básica de Hong Kong, el Comité Permanente ha incluido la Ley de Seguridad Nacional en una lista de normas nacionales con efectos jurídicos en el territorio de la Región Administrativa Especial de Hong Kong.

Dicha norma impone la creación de varios órganos regionales de composición mixta, con variada intervención de personalidades y órganos tanto regionales como nacionales, encargados de promover la salvaguardia de la seguridad nacional y perseguir delitos que la pongan en peligro. El enjuiciamiento de estos delitos es competencia de los órganos jurisdiccionales regionales, con las especificidades señaladas en la ley, aunque también se crea un órgano de gestión y composición estrictamente nacional, que ejercerá jurisdicción de forma excepcional en determinados casos tasados y muy graves.

Los delitos tipificados son los que, en el caso del Derecho Penal español, serían subsumibles grosso modo en los delitos contra la Constitución y, especialmente, en los delitos contra el orden público, aunque salvando las distancias, ya que se tratarían de realidades jurídicas aplicadas a realidades sociales bien distintas.

Las penas son, en general, severas. Oscilan desde la prisión permanente a lo que en el Derecho español podría equivaler a trabajos en beneficio de la comunidad, dependiendo del delito, su gravedad, sus efectos, el grado de participación y de las circunstancias particulares que puedan agravar o atenuar la responsabilidad criminal.

Se establecen algunas garantías como el principio de legalidad penal, el derecho a la asistencia letrada, a un juicio justo, a que el juicio se desarrolle en sesión pública salvo excepciones, etc.

Deja abierta la facultad de desarrollar esta ley a los órganos legislativos regionales, pero el desarrollo no podrá contravenir los mínimos indisponibles ya dispuestos por esta ley, quedando a discreción del Comité Permanente decidir sobre la adecuación o no de la normativa de desarrollo a la propia Ley de Seguridad Nacional.

En cuanto a la finalidad social que persigue esta ley, habrá que esperar para poder observar sus efectos. Pero, por lo que respecta a la finalidad política e institucional, y dado que el principio político de «un país, dos sistemas» no es incondicional e indefinido, puesto que en el año 2047 el régimen jurídico-político especial de la región expirará y todas sus instituciones

45. Promulgación de 30 de junio de 2020.

46. Lo que supone aplicar el principio de legalidad penal «nullum crimen nulla poena sine previa lege». 
pasarán a estar plenamente sometidas al sistema político y jurídico popular chino, es teóricamente un paso adecuado para una progresiva adaptación de las instituciones a la nueva realidad jurídica y política de un solo sistema que se impondrá en un futuro cercano, evitando así un brusco cambio institucional en la fecha señalada.

\section{Bibliografía}

Promulgación de la Ley de Seguridad Nacional por el Ejecutivo Hongkonés: https://www.gld.gov.hk/ egazette/pdf/20202444e/es220202444136.pdf (fecha de consulta 18/10/2020).

Traducción al inglés de la Ley de Seguridad Nacional, por la Agencia de Noticias Xinhua: http://www. xinhuanet.com/english/2020-07/01/c_139178753.htm (fecha de consulta 18/10/2020).

Presentación del borrador de la Ley de Seguridad Nacional ante la Asamblea Popular Nacional antes de su aprobación: http://spanish.xinhuanet.com/2020-05/22/c_139078233.htm (fecha de consulta 18/10/2020).

Ley Básica de Hong Kong y Constitución de la República Popular China: https://www.basiclaw.gov.hk/en/ basiclawtext/images/basiclaw_full_text_en.pdf (fecha de consulta 18/10/2020).

Declaración conjunta sino-británica de 1997: https://www.cmab.gov.hk/en/issues/jd2.htm (fecha de consulta 18/10/2020). 